\title{
La enarmonía: ser igual sin ser idéntico. Una reflexión sobre la igualdad de género
}

\author{
Francisco CAMAS GARCÍA \\ Universidad de Granada - Metroscopia \\ fcamasgarcia@gmail.com
}

Recibido: 3 de julio de 2014

Aceptado: 25 de octubre de 2014

\section{RESUMEN}

Este trabajo tiene como propósito reflexionar sobre la idea de igualdad desde una perspectiva de género. Más concretamente, este artículo plantea que la distancia actual entre la igualdad formal y la igualdad efectiva debe atajarse mediante un enfoque transformativo de los patrones socioeconómicos y culturales así como de las relaciones personales. Para ello, se vuelve decisivo afrontar dos cuestiones. Por un lado, la necesaria conjugación de la igualdad con la libertad y el pluralismo, entendiéndolos como valores interdependientes. Por otro, concebir la igualdad como un referente universal y ético. En este sentido, este artículo apuesta por el uso de una fórmula musical, la enarmonía, como la metáfora que quizás comprende mejor la idea y la práctica de la igualdad en las sociedades contemporáneas.

\section{PALABRAS CLAVE}

Igualdad, género, teoría feminista, teoría política.

\section{Enharmony: Being Equal without Being Identical. A Reflection on Gender Equality}

\begin{abstract}
This article reflects on the idea of equality from a gender perspective. Specifically, it states that the current gap between formal and effective equality should be addressed using a transformative approach to patterns of socioeconomic, cultural and personal relations. To do so, it is crucial to deal with two issues: the necessity to conjoin equality with freedom and pluralism, understood as interdependent values; and secondly, to conceive equality as a universal and ethical referent. In this sense, the article proposes the use of a musical formula, the enharmonic principle, as perhaps the best metaphor to understand the idea and practice of equality in contemporary societies.
\end{abstract}




\section{KEY WORDS}

Equality, gender, feminist theory, political theory.

En las sociedades democráticas contemporáneas la igualdad constituye un principio fundamental para la convivencia. Un principio que vincula a todas las personas en dignidad, respeto y derechos, independientemente de su condición o circunstancia. Es un valor que, como ocurre en el Estado español, se sitúa en lo más alto del ordenamiento jurídico y supone no solo la igualdad ante la ley sino también la ausencia de discriminación. Es una nota común, que la igualdad sea reconocida formalmente como eje articulador de la vida en sociedad.

Sin embargo, a pesar del reconocimiento normativo, lo cierto es que existe una distancia real entre la igualdad formal y la igualdad efectiva. Y, entre las razones de esa distancia, el género es una de las más importantes. Por ello, no solo se vuelve decisivo reflexionar sobre la igualdad desde la perspectiva de género sino, al mismo tiempo, plantear enfoques transformativos que aborden la sutura de esta brecha. Así pues, este artículo propone una reflexión y un enfoque, desde un punto de vista teórico, sobre la igualdad de género con la idea de reforzar algunos de los caminos abiertos por los feminismos para la construcción de sociedades más igualitarias.

La igualdad es una palabra polisémica, una voz polifónica que incluye ambigüedades y paradojas en su interior. Se trata de un concepto definitivamente complejo y que incluso en ocasiones se muestra como un ideal un tanto misterioso ${ }^{1}$. Ahora bien, contiene un elemento que es fundamental para comprender y hacer frente al intervalo entre lo formal y lo efectivo: la virtud de considerarse igual al mismo tiempo que particular. Se trata de una virtud que frecuentemente ha pasado desapercibida por la "perezosa razón occidental"2. De hecho, la tradición del pensamiento de occidente parece haber silenciado la convivencia de la igualdad con las diferencias y las particularidades. Así, se ha llegado a sostener la desafortunada costumbre de tratar la diferencia como desigualdad. Por lo tanto, este trabajo argumenta que el reto de la igualdad de género requie-

${ }^{1}$ Ronald Dworkin, Virtud soberana. La teoría y la práctica de la igualdad, Paidós, Barcelona, 2003, p. 21.

${ }^{2}$ Boaventura De Sousa SANTos, "La Sociología de las Ausencias y la Sociología de las Emergencias", Encuentro Renovar la teoría crítica y reinventar la emancipación social, p. 24. Disponible en: http://bibliotecavirtual.clacso.org.ar/ar/libros/edicion/santos/Capitulo\%20I.pdf (29-10-2014). 
re de una reflexión y un enfoque que permitan la emergencia de esta virtud y el desapego de tal abolengo. Estas ideas se desarrollan en dos planos.

En primer lugar, me dispongo a destacar la importancia del fundamento político del concepto de igualdad así como de algunas propuestas de gran reconocimiento en el pensamiento occidental. La materialización de la igualdad, como a menudo se dice, parece asentarse en un ámbito al cual las leyes no llegan, por lo que se tornan necesarios planteamientos que se dirijan no solo a los derechos y los deberes, sino también hacia las condiciones y las circunstancias, los recursos y las oportunidades. Se detendrá la mirada en las propuestas de la igualdad distributiva de John Rawls (1921-2002), Amartya Sen y Ronald Dworkin (1931-2013) con el objetivo de atender sintéticamente al enfoque políticoeconómico de la igualdad como referentes de dicho pensamiento.

En segundo lugar, se dibuja el plano de las críticas y las reivindicaciones feministas, que permite engarzar la cuestión de género con la igualdad. Esta idea se traduce, a su vez, en dos propuestas. Por un lado, el marco universalista y ético de manos de Seyla Benhabib y, por otro, el enfoque transformativo bifronte de Nancy Fraser sobre las dimensiones de la redistribución y del reconocimiento en la concepción de la igualdad.

A través de estos dos planos, la igualdad de género se plantea como un reto enarmónico, es decir, articulado a través de una fórmula que permite reactivar la virtud de considerarse igual a la vez que particular. Para ello, un primer paso es pensar la igualdad como un valor interdependiente de la libertad y el pluralismo, es decir, como partes de la misma virtud política. Como argumento más adelante, esta conjugación de valores es incompatible con el prisma conflictual que entiende la relación entre ellos como un campo de batalla ${ }^{3}$ axiológico en donde la defensa de uno conlleva inevitablemente el sacrificio de otro. Si la virtud enarmónica supone la consideración simultánea de iguales y particulares, entonces la igualdad solo puede florecer junto a la libertad y al pluralismo. Por lo tanto, la enarmonía se vuelve la herramienta teórica que con mayor soltura expresa el sentido de la igualdad de género, pues a modo de metáfora política permite igualar sin identificar y liberar sin discriminar, es decir: hace posible ser igual sin ser idéntico.

${ }^{3}$ Zygmunt Bauman, Identidad, Losada, Madrid, 2005, p. 165. Citado en Octavio SalazAr, Cartografias de la igualdad. Ciudadanía e identidades en las democracias contemporáneas, Tirant lo Blanch, Valencia, 2010, p. 49. 


\section{LA IDEA DE IGUALDAD}

La igualdad se comprende como una condición que une o vincula a todas y cada una de las personas al margen de sus atributos y particularidades. No niega, pues, la existencia de determinadas diferencias sino que simplemente no las contempla como elementos decisivos para su articulación. Lo que la igualdad propugna es el rechazo de la desigualdad, ya sea por una traducción de esas diferencias en desigualdades o por cualquier otro motivo. No obstante, es inadecuado entender la igualdad únicamente como ausencia de desigualdad, pues esto conllevaría despojarla de entidad propia. Por lo tanto, el reconocimiento innegable de desigualdades restringe el motor de la igualdad pero no frena, si se quiere, su perspectiva teórica genuina.

Tampoco se trata de indagar si, como dice Giovanni Sartori, la igualdad es "la menos natural de todas las formas políticas"4 y se establece como consecuencia de la desigualdad o, siguiendo a Jean-Jacques Rousseau (1712-1778), en realidad puede ser el resultado de la corrupción de la otra ${ }^{5}$. Más bien, se plantea como un valor inherente al individuo que no necesita tanto determinar las causas de tan poca naturalidad o su origen, sino de qué contenido teórico dispone para desplegar su propósito. Para ello, en este artículo se propone situar aquellos aspectos políticos de relevancia que nutren el concepto de forma que se esclarezcan algunas confusiones frecuentes. Así pues, a continuación me detengo en la noción de inherencia y en las propuestas de la igualdad distributiva.

La idea de igualdad responde a una avenencia o convención artificial ${ }^{6}$ apoyada en una concepción del ser humano y a la que este le da vida. En efecto, no podría tratarse de una imagen abstracta que desde la lejanía definiera la condición humana. Atiende más bien a la (auto) atribución de una condición propia o intrín$\mathrm{seca}^{7}$ que concibe y considera iguales a todas las personas. Esto no tiene por qué suponer el reconocimiento en la condición humana de características naturales o biológicas que vinculen de manera esencial o sustancial el cuerpo y las capacidades. Si las diferencias biológicas no se traducen inexorablemente en desigualdades, no tienen cabida en el debate de la igualdad. Por ello, las comunes confusiones entre igualdad e identidad y entre desigualdad y diferencia deben ser aclaradas.

\footnotetext{
${ }^{4}$ Giovanni SARTori, Aspectos de la democracia, Limusa-Wiley, México, 1965, p. 329.

${ }^{5}$ Jean-Jacques Rousseau, Discurso sobre el origen y los fundamentos de la desigualdad entre los hombres, Península, Barcelona, 1970.

${ }^{6}$ En el sentido griego de techné, arte o artificio humano.

${ }^{7}$ Sobre la idea de igualdad intrínseca puede verse Robert DAHL, La democracia y sus críticos, Paidós, Barcelona, 1992.
} 
La igualdad no se corresponde con la simetría o la comparación idéntica entre dos personas sino que manifiesta el reconocimiento igual en dignidad, trato y respeto de las mismas. Podría ser, como dice Sartori, que tal confusión pueda producirse por motivos semánticos, ya que tanto en español como en francés, italiano y alemán decir que "dos cosas son iguales equivale a decir que son idénti-

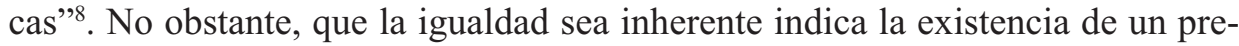
supuesto fundamental para la convivencia entre las personas: que todas deben ser respetadas y consideradas por igual. En este sentido, también constituye un principio normativo y ético que rige el desarrollo personal y la interrelación entre los individuos. Y, por último, no se concibe en términos de simetría, de comparación idéntica ni de consideración homogénea, sino que iguala en trato e importancia.

Sin embargo, se suele insistir en que esta idea de igualdad normativa, que se sostiene previamente y durante la vida de toda persona, no puede evitar toparse con una contradicción fundamental respecto a la desigualdad. Cuando la noción de justicia entra en escena, se dice, un trato siempre igual a todas las personas puede ser injusto porque no combate realmente las desigualdades existentes. Dicho de otra forma, para que tanto la igualdad normativa como efectiva sean justas no basta con un trato igual sino que, al mismo tiempo, se requiere de un trato diferente respecto a los que se encuentran en una situación de discriminación. Esta idea se ve con bastante nitidez en el dilema clásico de la igualdad de oportunidades.

La igualdad de oportunidades hace referencia a la ausencia de discriminación por cualquier condición o circunstancia en los procesos de acceso a cualquier posición social, política, económica o de cualquier otro tipo ${ }^{9}$. Ahora bien, un reconocimiento formal de esta ausencia de discriminación o neutralidad para el igual acceso, derecho o acción no es suficiente para la igualdad, pues las condiciones y circunstancias de partida influyen en los resultados de tales oportuni-

\footnotetext{
${ }^{8}$ Algo que quizás sea posible distinguir en inglés mediante equal y same, aunque de todos modos ambas se utilizan frecuentemente como sinónimos. SARTORI, Aspectos de la democracia, p. 331.

${ }^{9}$ La igualdad de oportunidades enfatiza los términos legales y procedimentales para proveer un acceso igual a las posiciones que permiten alcanzar bienes en sociedad. En resumen, asume lo injusto de que factores más allá del control de un individuo como puede ser su sexo o raza, condicionen de forma importante sus oportunidades en la vida. Sobre esta noción puede acudirse a: Nicole Richardt y Torrey Shanks, "Equal Opportunity", en William A. DARITY Jr. (ed.), International Encyclopedia of the Social Sciences, Second Edition, vol. 2, Thomson Gale, Michigan, 2008, pp. 611-614; Andrew MASON, "Social Justice: The Place of Equal Opportunity", en Richard BeLLAMY y Andrew Mason (eds.), Political concepts, Manchester University Press, Manchester \& New York, 2003, pp. 28-40; Thomas Nagel, "Equality", en Matthew Clayton y Andrew Williams (eds.), The Ideal of Equality, St. Martin's Press, New York, 2000, pp. 60-80.
} 
dades. Si se toma el ejemplo de Robert Dahl sobre la igual oportunidad de participación política de ciudadanos con estatus socioeconómicos dispares, se entiende que aquel que tenga más recursos, mayor formación y mejores medios participará y ejercerá más influencia en las decisiones políticas ${ }^{10}$. Por ello, la igualdad de oportunidades debe combinarse con una redistribución de los recursos - no solo entendidos en sentido material- Para combatir las desigualdades no solo es necesario un establecimiento formal de igual trato y oportunidades sino que se deben remover los obstáculos que impiden una igualdad efectiva.

Ahora bien, este pertinente trato diferenciado que compensa las situaciones de discriminación mediante la redistribución de los recursos y/o acciones positivas no debe entenderse como contradictorio sino, en realidad, complementario en la concepción de la igualdad ${ }^{11}$. En este sentido, la remoción de la histórica discriminación que atañe a las mujeres, como se ve más adelante, conlleva no solo una transformación de las estructuras formales para que se garantice un reconocimiento efectivo de la igualdad sino también de las estructuras políticas, sociales y culturales que provocan esa marginación y que condicionan sustantivamente la efectividad del principio igualitario ${ }^{12}$.

Por lo tanto, conviene ahora detenerse en las propuestas redistributivas como aquellas posiciones clave que complementan las dimensiones formal y efectiva.

\section{LA IGUALDAD DISTRIBUTIVA}

Es común en la tradición del pensamiento político contemporáneo distinguir entre diferentes tipologías de la igualdad ${ }^{13}$. Esta pluralidad reconocida por el debate político contemporáneo, según Thomas Nagel, puede sintetizarse en cua-

${ }^{10}$ DAHL, La democracia y sus críticos, pp. 141-142.

${ }^{11}$ En ocasiones, esta idea se expresa como lo preciso de un trato desigual a los desiguales y un trato igual a los iguales. La propia redistribución de recursos mediante imposiciones fiscales por ejemplo no sería justa si gravara por igual a rentas altas y bajas, de ahí que un trato desigual a los desiguales sea tan igualitario como un trato igual a los iguales en tanto un valor inherente a las personas. Puede consultarse a este respecto los criterios tradicionales y operacionales del igualitarismo en: Felix E. OppenheIM, "Igualdad", en David L. Sills (dir.), Enciclopedia Internacional de las Ciencias Sociales, vol. 5, Aguilar, Madrid, 1975, pp. 615 y ss. También son pertinentes a este respecto los elementos de la igualdad resaltados en SARTORI, Aspectos de la democracia, y Giovanni SARTORI, Elementos de teoría política, Alianza, Madrid, 1999.

${ }^{12}$ Salazar, Cartografías de la igualdad, p. 79.

${ }^{13}$ SARTORI, Aspectos de la democracia; SARTORI, Elementos de teoría politica; NAGEL, "Equality"; OpPENHEIM, "Igualdad". 
tro tipos de igualdad interrelacionadas: política, legal, social y económica ${ }^{14}$. No obstante, siguiendo a este autor, la igualdad real depende en gran medida de factores económicos. Las grandes diferencias de riqueza e ingresos producen distinciones más allá de la garantía formal de un mínimo estatus social a partir de la igualdad política, legal y social ${ }^{15}$. De ahí que tres de los teóricos igualitaristas más renombrados centren sus propuestas en el ámbito de la igualdad distributiva. A pesar de sus notables diferencias, Rawls, Dworkin y Amartya Sen pueden sintetizar a ojos de este trabajo las perspectivas que atienden a la dimensión efectiva - o en ocasiones sustantiva - de la igualdad. A continuación se realiza un breve repaso por ellas.

Según Dworkin, la igual consideración de todas las personas es un principio primordial para cualquier Estado o gobierno democrático ${ }^{16}$. Ahora bien, otorgar la misma importancia a las personas no significa equipararlas sustancialmente sino, y esto es importante, materialmente. Esto es, la igualdad exige que un gobierno tenga como aspiración la igualdad de recursos al margen de las condiciones personales como el género, la raza, la lengua, etc. Por consiguiente, lo relevante es lo que las personas puedan llegar a $\operatorname{ser}^{17}$ y no que sean y/o vivan de la misma forma. Dicho de otro modo, la igualdad entendida como distribución de recursos debe versar en un reparto igualitario de los mismos para que cada cual pueda elegir y desarrollar su vida y no para que todas las elecciones y los desarrollos fruto de la distribución sean considerados iguales. Por tanto, la propuesta de la igualdad deviene en una política (re)distributiva o de administración eficaz y razonable de los recursos ${ }^{18}$. No se centra la mirada en los fines de la igualdad sino en los recursos para alcanzar esos fines.

En una línea similar, Amartya Sen sostiene que la igualdad distributiva efectivamente debe centrarse en la libertad de elección y desarrollo o, dicho con sus propias palabras, en "la oportunidad real que tenemos de alcanzar aquello que valoramos"19. Así, coincide con Dworkin en que el reparto igualitario de los

${ }^{14}$ NAGEL, "Equality", p. 60. No obstante, existen otras tipologías como la de Sartori: igualdad jurídico-política, igualdad social, igualdad de acceso, igualdad de partida e igualdad económica, SARTORI, Elementos de teoría política, p. 103.

${ }^{15}$ NAGEL, "Equality", p. 60.

${ }^{16}$ DwORKIN, Virtud soberana, p. 141.

${ }^{17}$ Algo que se debe complementar, según Dworkin, con el "principio de la responsabilidad especial", es decir, "que el gobierno trabaje...para conseguir que el destino de la gente dependa de lo que elige". Ibid., p. 16.

18 "Una división equitativa de recursos supone un mercado económico de algún tipo, como institución política real". Ibid., p. 75.

${ }^{19}$ Amartya K. SEn, Nuevo examen de la desigualdad, Alianza, Madrid, 1995, p. 45. 
recursos es de suma importancia, pero añade que este no debería ser el objetivo final, pues, de ser así, se corre el riesgo de inocular el principal propósito: la libertad.

Sen entiende que la libertad de las personas para llevar un tipo de vida $u$ otro no se sostiene solamente a partir de una igualdad material, sino que tiene su leitmotiv en la capacidad de traducir los recursos en funcionamientos o estados y acciones valiosos. De ahí que apueste por una política de igualdad distributiva centrada en el bienestar ${ }^{20}$ de las personas y no exclusivamente en los recursos. No obstante, como reconoce Gerald A. Cohen (1941-2009), lo que Sen denomina capacidad no es exactamente o únicamente bienestar sino algo similar a la oportunidad $^{21}$. En esto último coincide Dworkin, aunque advierte que sería una falacia suponer que el objetivo político último sea la igualación de capacidades para lograr bienestar en lugar de centrarse en "convertir a las personas en iguales respecto de los recursos que necesitan para lograr la felicidad, el auto-respeto y otros anhelos similares"22.

Por último, el autor considerado referente de la tradición político liberal respecto a la conceptualización político-económica de la igualdad ${ }^{23}$, Rawls, plantea bajo el paradigma de la tradición contractualista en Teoría de la justicia los principios de justicia que, a su modo de ver, una sociedad necesita a la hora de redistribuir los recursos ${ }^{24}$. La propuesta de este pensador ha sido debatida y criticada ampliamente $y$, en este sentido, solo se pretende apuntar lo relevante para este trabajo: la noción de redistribución de los bienes primarios como requerimiento complementario a la igualdad de oportunidades. Para este autor, la igualdad de

${ }^{20}$ El debate teórico entre los defensores y detractores del uso del bienestar como referente para concebir la igualdad queda lejos del propósito de este trabajo. No obstante, sí es oportuno apuntar que Sen no entiende el bienestar en tanto estado reductible a una utilidad, unos recursos, bienes o ingresos determinados, sino más bien como el proyecto de vida buena que permite la libertad para convertir estos medios en capacidades para funcionar. A este respecto, Dworkin argumenta que tal propósito no es realmente compatible con la libertad, ya que inevitablemente cualquier teoría del bienestar se apoya en un tipo de valoración de este, o bien, como estado de satisfacción consciente (ya sea interés, deseo, placer, felicidad, etc.) o bien, del éxito de la conversión de los recursos en bienestar. Con lo cual, independientemente de la importancia del desarrollo de las capacidades, la libertad queda condicionada por la valoración del logro de bienestar. Ibid., pp. 51 y ss.; DwORKIN, Virtud soberana.

${ }^{21}$ Gerald A. CoHen, “iIgualdad de qué? Sobre el bienestar, los bienes y las capacidades”: Comercio Exterior, vol. 53, n. ${ }^{\circ} 5$ (2003), pp. 427-433.

${ }^{22}$ Dworkin, Virtud soberana, p. 329.

${ }^{23}$ Según Nagel, la teoría de Rawls es la visión igualitarista liberal más desarrollada y sobre la que se centra mayormente el debate contemporáneo sobre la igualdad. NAGEL, "Equality", p. 63.

${ }^{24}$ John Rawls, Teoría de la justicia, Fondo de Cultura Económica, México, 2006. 
oportunidades debe ser combinada con una redistribución de los bienes primarios: ingresos, riqueza, oportunidades y bases del respeto a sí mismo (selfrespect). Solo de esta forma, se dice, se puede equilibrar las desventajas existentes entre los individuos fruto de factores arbitrarios o más allá del control de una persona, como pueden ser el género, la raza o el estatus socioeconómico.

Ciertamente, estos tres autores ponen énfasis en la igual distribución de recursos como propuesta necesaria y decisiva, y también en la libertad como principio fundamental, de cara a reducir la distancia entre la igualdad formal y la igualdad efectiva. A ojos de Nancy Fraser, estos teóricos igualitaristas se centran en el "qué" de la igualdad, es decir, quedan inmersos en una tradición analítica en la que se discute qué es lo que debe distribuirse ${ }^{25}$. Básicamente, la discusión gira alrededor de "los pros y los contras de derechos, recursos, bienes primarios, oportunidades, libertades reales y capacidades como sistemas de medición alternativos para evaluar la justicia de las relaciones sociales"26.

Sin embargo, en esta tradición de la igualdad distributiva subyacen algunos interrogantes clave para el propósito del presente artículo. Entre ellos, se destacan tres. Primero, puede cuestionarse si la igualdad es al fin y al cabo una mera cuestión de reparto igualitario de los recursos. Segundo, si la redistribución debe ser moralmente neutral, es decir, si debe quedar al margen no solo de la consideración de factores como el género, la orientación sexual o las creencias religiosas sino de las concepciones morales que puedan existir respecto a lo que es una vida buena. Y, tercero, hasta qué punto un énfasis en la libertad individual basada en las capacidades y en las oportunidades como referente puede ser compatible con la igualdad.

Para tratar de hacer frente a estas cuestiones, en primer lugar, se sigue la propuesta de Ronald Dworkin respecto a la hipótesis del conflicto entre la libertad y la igualdad. En segundo lugar, se defiende la perspectiva ética en el planteamiento universalista de Seyla Benhabib. Y en tercer lugar, se plantea que la igualdad no puede limitarse a una redistribución de recursos o bienes primarios, sino que supone un reto que debe apuntar a la transformación de la estructura socioeconómica y de la estructura cultural y simbólica, lo cual en este trabajo supone introducir las aportaciones de las teorías feministas al concepto de igualdad.

\footnotetext{
${ }^{25}$ Nancy Fraser, Escalas de justicia, Herder, Barcelona, 2008, p. 68.

${ }^{26}$ Ibidem.
} 


\section{IGUALDAD, LIBERTAD Y COMUNIDAD}

Los enfoques de la igualdad distributiva, como se ha visto, enfatizan la dimensión económica atendiendo tanto al reparto igualitario de los recursos como a la libertad de elección. Así, la cuestión de la igualdad parece poder contestarse desde una política de distribución de recursos, ya sea concentrada en el reparto equitativo o en la traducción de tal reparto en bienestar. Esto podría dar lugar a interpretaciones a partir de las cuales la garantía de (re)distribución determinaría el ámbito de la igualdad, mientras la libertad de elección constituiría un ideal político independiente anclado en los intereses, las preferencias y las decisiones individuales. Por ello, ¿sería muy descabellado pensar que una perspectiva de la igualdad más allá de la igual consideración y el reparto equitativo de recursos, pueda invadir las competencias de la libertad? De ser así, la mera (re)distribución podría verse como un condicionante a la autonomía individual de elegir la cantidad o el tipo de recursos a los que se aspira, pues la libertad de elección quedaría subordinada a la igualación. ¿Quiere decir esto que dar la misma importancia a la libertad y la igualdad provocaría un conflicto irreconciliable entre ambas? ¿Se trataría de elegir cuál de los dos principios debería preponderar para evitar una más que posible incompatibilidad? Las respuestas a estas preguntas, siguiendo a Dworkin, son decididamente políticas.

En primer lugar, puede intuirse que el cuestionamiento por incompatibilidad o conflicto entre la igualdad y otros valores tiene que ver con una concepción particular del pluralismo. Según Isaiah Berlin (1909-1997), por ejemplo, la experiencia parece mostrar que la conciliación entre valores es falsa, pues el énfasis en uno conlleva un inevitable sacrificio pleno o parcial de otros ${ }^{27}$. El acento en la libertad individual, se dice, encuentra dificultades ante aspiraciones igualitarias porque merman su desarrollo y viceversa. Por tanto, se está ante una idea del pluralismo que encierra una visión enfrentada de los valores y que parece desembocar en una incompatibilidad ineludible entre ellos.

Sin embargo, llegar a una idea del pluralismo como tal depende, en realidad, de qué idea se tenga de cada valor, ya que en esas concepciones es donde se encuentra la causa del conflicto. En este sentido, tal y como Dworkin lo ve, que surja un conflicto entre la libertad y la igualdad depende, por ejemplo, de qué se entienda por igualdad, de forma que el conflicto puede darse "con algunas con-

${ }^{27}$ Isaiah BerLin, El fuste torcido de la humanidad, Península, Barcelona, 1992. Desde una concepción radical del pluralismo puede acudirse a Chantal Mouffe y Marco A. GaLmarini, El retorno de lo político: comunidad, ciudadanía, pluralismo, democracia radical, Paidós, Barcelona, 1999. 
cepciones de la igualdad, pero no con otras" ${ }^{28}$. Con lo cual, una idea de igualdad tal y como en este artículo se desarrolla no solo no es incompatible con la libertad sino que, junto con otros valores, se considera parte de una única virtud política, pues estos valores se autodefinen mutuamente ${ }^{29}$.

La argumentación es claramente intuitiva. Por un lado, la igualdad supone reconocer la libertad de todos los individuos por igual mientras que, por otro, la libertad permite que exista una igual consideración de todos los individuos. Dicho de otra manera: la forma genuina en virtud de la cual las personas son libres estriba en la igualdad de consideración, al mismo tiempo que las personas son igualmente consideradas cuando se les reconoce su libertad ${ }^{30}$.

$\mathrm{Y}$, en segundo lugar, para que tal interdependencia pueda ser efectiva no basta con una política económica redistributiva de recursos y garante de la libertad de elección. Además, se precisa de alguna noción decididamente política, esto es, una dimensión pública, que articule la igualdad, la libertad y el pluralismo. Esto es así, según Dworkin, ya que las vidas de las personas y de la comunidad están inevitablemente integradas, por lo que el éxito de esta interdependencia en la ciudadanía ${ }^{31}$ repercute en el individuo y viceversa. Así pues, se requiere del apoyo en una perspectiva cívica ${ }^{32}$.

En definitiva, se concluye, no se trata de someter la igualdad a la libertad o la libertad a la igualdad. La hipótesis del conflicto queda descartada en una noción abierta del pluralismo. Desde un punto de vista teórico, estos principios no solo son compatibles sino, a la vez, necesarios en su interdependencia para la articulación de la vida en democracia. A este respecto, la concepción de la ciudadanía democrática se vuelve fundamental si se entiende que la vida de las personas y la comunidad convergen de forma evidente. Por tanto, Dworkin enfatiza que la libertad, la igualdad y el pluralismo no son realmente tres virtudes políticas distintas o independientes que viven en conflicto sino que se trata de "aspectos complementarios de una sola concepción política, de forma que no podemos proteger, ni siquiera entender, estos tres ideales de forma independiente" ${ }^{33}$. Aunque en este trabajo no se comparta su propuesta de medir la igualdad básicamente

${ }^{28}$ DwORKIN, Virtud soberana, p. 144.

${ }^{29}$ Ibid., p. 200.

30 "La libertad es crucial para la justicia política porque una comunidad que no proteja la libertad de sus miembros no los trata — no los puede tratar — con igual consideración”. Ibid., p. 199.

${ }^{31}$ Dworkin no concibe la comunidad como unión interesada de individuos sino como una entidad con una lógica propia en donde confluyen relaciones individuales y colectivas. Ibid., p. 244.

${ }^{32} \mathrm{El}$ autor atribuye esta perspectiva a la idea de republicanismo cívico. Ibidem.

${ }^{33}$ Ibid., p. 259. 
en términos de recursos y oportunidades, su propuesta de conjugación de estos valores es probablemente la más adecuada para un enfoque de la igualdad de género.

\section{IGUALDAD Y UNIVERSALISMO ÉTICO}

El origen de la idea de igualdad como distribución de recursos desde un punto de vista económico no es reciente ni exclusivo del pensamiento contemporáneo. Ya en la antigua Grecia, recuerda Bernard Manin, se distinguían dos tipos de igualdad distributiva ${ }^{34}$. Por un lado, la igualdad aritmética, mediante la cual todos los miembros de un grupo recibían idénticas proporciones de recursos. Y, por otro lado, la igualdad geométrica, que efectuaba un reparto proporcional de los recursos entre los individuos de acuerdo a algún criterio determinado. Pero aparte de la existencia de un prisma económico, la idea de igualdad tiene dos raíces que son genuinamente políticas y sobre las que es preciso detenerse: la isegoría y la isonomía. Aunque su experimento pueda catalogarse de "efímero" en las democracias griegas ${ }^{35}$, ambas se encuentran en la génesis de lo que actualmente se entiende por democracia ${ }^{36}$.

Por una parte, la isegoría refiere a la capacidad retórica —o el derechopara decir, para participar en igualdad en el espacio público; y, por otra, esta conduce a la isonomía o "a la posibilidad de ingeniar nuestras propias leyes, que componemos como partituras con las que armonizamos algo nuestras vidas" ${ }^{\prime 37}$. La igualdad de participación y ante la ley se asienta como principio democrático cardinal. No obstante, como nos recuerda Hannah Arendt (1906-1975), esto únicamente se aplicaba al ámbito público. Se trataba de una igualdad de pares que presuponía la existencia de desiguales en el resto de espacios, como el del $\operatorname{hogar}^{38}$. De ahí, que la libertad de isegoría e isonomía se alzaba como bien de privilegio reservado a determinados miembros exclusivos ${ }^{39}$.

${ }^{34}$ Bernard MANIN, Los principios del gobierno representativo, Alianza, Madrid, 1998, pp. 51 y ss.

${ }^{35}$ SARTORI, Aspectos de la democracia, p. 337.

${ }^{36}$ Javier Roiz sitúa el derecho de isegoría e isonomía —en la construcción del espacio público- en el mismo origen de la teoría política. De esta forma, política e igualdad son notas del mismo acorde pues hacen brotar, dice Roiz reflexionando sobre el pensamiento de Arendt, "el bios theoreticos o forma de vida reflexiva y expresada en el diálogo entre iguales". Javier RoIz, La recuperación del buen juicio. Teoría política en el siglo XX, Foro Interno, Madrid, 2003, p. 166.

${ }^{37}$ Ibid., p. 18.

${ }^{38}$ Hannah ARENDT, La condición humana, Taurus, Madrid, 2005.

${ }^{39} \mathrm{Sin}$ embargo, era constatable que "las personas del interior del hogar, los esclavos, los bárbaros o los dedicados a la defensa pública, son el soporte que garantiza que los fundadores de la 
No es hasta bien entrada la Edad Moderna cuando comienza a consolidarse una noción abierta de la igualdad ${ }^{40}$. De alguna forma, la plasmación de los valores ilustrados en los principios constitutivos de las democracias contemporáneas deviene en una conceptualización de la igualdad erigida sobre una idea de justicia. Se trata de una justicia inclusiva, que comprende a todas las personas y todos los ámbitos - no solo el público-y que, por consiguiente, constituye la igualdad en un valor universal. No obstante, esta universalidad devenía en una ficción erigida desde el pacto ilustrado: la promesa de la emancipación de las garras del Antiguo Régimen mediante el principio igualitario era solo una realidad para los hombres. Las mujeres quedaban excluidas "como aquel sector que las Luces no quieren iluminar"41. Sobre esto se volverá más adelante.

Ahora bien, ¿qué consecuencias tiene actualmente desde una perspectiva teórico-política una conceptualización de la igualdad como principio universal? En principio, puede ser evidente que supone la extensión de forma indiscrimina$d a$ de la igualdad de consideración, trato, oportunidad, dignidad y respeto, de igualdad isegórica e isonómica, a todas las personas. Sin embargo, en la línea general de la crítica posmodernista ${ }^{42}$, como bien apunta Benhabib, buena parte de las teorías universalistas, como las de corte contratista $^{43}$, han contemplado únicamente la dimensión abstracta de la universalidad. Esto se traduce, según la

polis puedan entregarse a la aventura de recrear la ciudad y de mantenerla viva con sus acciones. Es como si ellos fueran los únicos que sacan el cuello de las aguas de la necesidad y de la pereza, subidos en los hombros de todos los que atienden mientras tanto en la oscuridad de las tareas privadas o subordinadas". RoIz, La recuperación del buen juicio, p. 167.

${ }^{40}$ Sobre la incidencia de la Modernidad en el concepto de igualdad puede acudirse a Marshall BERMAn, Todo lo sólido se desvanece en el aire. La experiencia de la modernidad, Siglo XXI, México, 2006.

${ }^{41}$ Cristina Molina Petit, Dialéctica feminista de la Ilustración, Dirección General de la Mujer, Barcelona, 1994, p. 29. Citado en SAlazAR, Cartografías de la igualdad, p. 63.

${ }^{42} \mathrm{Si}$ bien los procesos sociales que dan lugar, como agudamente señala Marshall Berman, a la vorágine de la Modernidad permiten unos avances decisivos en la consolidación de determinados valores, esto se produce de forma paradójica y contradictoria. Así pues, al mismo tiempo que la Modernidad se puede concebir a partir de una visión abierta, procesual y dinámica también puede serlo de manera cerrada, estática y monolítica. Por lo tanto, la noción de igualdad puede ser tanto un espacio abierto que se cultive en el reconocimiento de la contingencia de la vida humana como un espacio cerrado que se halle en un inevitable conflicto a expensas de una solución definitiva a su definición. Para el concepto de Modernidad aquí expuesto puede acudirse a BERMAN, Todo lo sólido se desvanece en el aire. Sobre la noción abierta del concepto, esa mano abierta frente al puño cerrado, véase la lectura que Javier Roiz realiza del pensamiento de Marco Fabio Quintiliano. RoIz, La recuperación del buen juicio, pp. 31-34, 63-64.

${ }^{43}$ Benhabib reúne en el pensamiento liberal convencional o en las teorías clásicas de la universalidad a autores como Rousseau, Locke o Rawls. 
autora, en que al final el ser se comprende en realidad "no integrado e incorpóreo" ${ }^{44}$, es decir, sin identidad materializada ${ }^{45}$. De esta forma, la idea de igualdad es universalizada de forma ficticia, cayendo en un oxímoron: personas incorpóreas o no encarnadas. Así pues, si se parte de la idea de que la igualdad no puede separarse de la idea de sujeto o agente, entonces este no puede permanecer únicamente en el campo de la abstracción, como un sustrato o un ente aislado. En última instancia, esa representación abstracta del ser como "otro generalizado" 46 , sin cuerpo ni voz particular, es solo la mitad de la historia. Se requiere igualmente de su concreción, especificidad y particularidad. Este otro generalizado precisa, pues, de un "otro concreto" que nos haga ver "a cada ser racional como un individuo con una historia, identidad y constitución afectivo-emocional concreta" $"$.

De hecho, si se enfatiza el elemento político de la isegoría en la idea de igualdad, la presencia complementaria del otro generalizado y del otro concreto es fundamental, pues nos revela la importancia de la interactividad, de la capacidad de abstraernos y concretarnos tanto en el foro interno como en el foro externo. Como señala Javier Roiz, es decisiva la distinción entre hablar y decir porque la importancia del fundamento isegórico de la política no reside tanto en el hablar como en el ser escuchado ${ }^{48}$. El decir conlleva implícito el ser escuchado, es decir, el reconocimiento del otro, que escucha y que es igualmente partícipe en la interlocución. Así pues, siguiendo este argumento retórico, la universalidad de la igualdad asume en el derecho a decir — de escuchar y ser escuchado-, a esos otros en abstracto y en concreto iguales al margen de su individualidad y atendiendo a su identidad en el curso de la comunicación. Es la importancia que las voces ausentes y presentes tienen en el discurso político ${ }^{49}$.

$\mathrm{Si}$ se asume que de nada sirve una igualdad escrita sobre el papel si no se traduce en una igualdad efectiva, entonces solo una universalidad en abstracto no es suficiente. Es la igualdad un concepto político precisamente porque atiende a

${ }^{44}$ Seyla BenHABIB, El ser y el otro en la ética contemporánea. Feminismo, comunitarismo, posmodernismo, Gedisa, Barcelona, 2006, p. 176.

${ }^{45}$ Ibidem.

${ }^{46}$ Para Benhabib, "el punto de vista del otro generalizado nos exige ver a todos y cada uno de los individuos como seres racionales a los que les corresponden los mismos derechos y deberes que quisiéramos atribuirnos a nosotros mismos". Ibid., p. 182.

${ }^{47}$ Ibid., p. 183.

${ }^{48}$ RoIz, La recuperación del buen juicio, p. 166.

${ }^{49}$ Ello se resume de forma clara en la recensión que Fernando Fernández-Llebrez realiza de la obra El mundo interno y la política de Javier Roiz. Para acudir a la recensión véase Revista Española de Ciencia politica, n. ${ }^{\circ} 34$ (2014), pp. 235-239. Para una inmersión directa: Javier RoIz, El mundo interno y la política, Plaza y Valdés, Madrid, 2013. 
un proceso constructivo y transformativo en el que las personas no son definidas virtualmente sino que son agentes portadores de identidades concretas que hacen suya la idea y la traducen en acciones, discursos y hechos.

Esta consideración de la singularidad de los individuos conlleva, pues, imprimir un carácter ético al ideal universalista de la igualdad que atiende a la pluralidad de formas y concepciones del bien. Desechando concepciones asépticas o unívocas del bien, un universalismo genuino no puede ser moralmente neu$\operatorname{tral}^{50}$. Por el contrario, un enfoque universalista ético se asienta en la defensa de unos valores elementales, como la igualdad, que no se compromete con ninguna concepción del bien particular. En efecto, el universalismo ético preserva la igualdad al tiempo que respeta cada florecimiento y autonomía individuales; respeta la existencia de distintas concepciones de lo que es una vida buena. Se trata, en última instancia, de otro ángulo de la necesaria interdependencia entre la libertad y la igualdad y de la distinción entre iguales e idénticos. Que toda persona sea tratada "como un fin y como una fuente de participación activa y de valía en sí misma" ${ }^{51}$ significa adoptar una postura abierta, inclusiva y situada.

Por tanto, el universalismo no se agota en el cuestionamiento de su imparcialidad al considerar únicamente el criterio de abstracción. Si se logran "clarificar sus propios supuestos injustificados" 52 a partir de un posicionamiento ético y desde la perspectiva complementaria entre sujetos abstractos portadores de derechos y sujetos concretos protagonistas de historias de vida, entonces este enfoque no es solo válido sino necesario para una aproximación teórica a la igualdad como la que aquí se expone. Es a partir de la combinación y la tensión crítica entre la generalidad y la concreción cuando los individuos son considerados en términos universalmente igualitarios.

Únicamente a través de una perspectiva inclusiva de este tipo puede alcanzarse una ética pública con carácter universal. Una ética que dé forma a instituciones formales, a un mismo marco normativo y que articule la formación de prácticas acordes al cultivo de valores cívicos comunes. Afrontar el compromiso universalista igualitario que inspira esta ética, requiere además de un proceso de apertura del pensamiento a la perspectiva de los otros. Pensar desde nuestra indi-

50 "La neutralidad es un término más bien sin vida y sin forma en la defensa de los valores...Lo que debe indicarse con el término 'neutralidad' es que las normas materializadas en las instituciones legales y públicas de nuestras sociedades deben ser lo suficientemente abstractas y generales como para permitir que florezcan muchos modos de vida diferentes y muchas concepciones diferentes del bien". BENHABIB, El ser y el otro en la ética contemporánea, p. 60.

${ }^{51}$ Martha NussBaum, Las mujeres y el desarrollo humano, Herder, Barcelona, 2002, p. 110.

${ }^{52}$ BenHABIB, El ser y el otro en la ética contemporánea, p. 67. 
vidualidad es también pensar desde el punto de vista de los otros como sujetos morales. Esto, siguiendo a Benhabib,

Entraña compartir una cultura pública en la que todos los demás puedan articular lo que piensan y mostrar cuáles son sus perspectivas...El cultivo de la propia imaginación moral florece en una cultura en la que la perspectiva egocéntrica del individuo es cuestionada constantemente por la multiplicidad y diversidad de perspectivas que constituyen una vida pública ${ }^{53}$.

En definitiva, se deja constancia de que las nociones de lo universal, lo humano o lo público en esta idea de la igualdad no se corresponden con concepciones totalizantes. De ser así bastaría con la suma de sinécdoques, de tomar el todo por una de sus partes o una parte por el todo ${ }^{54}$, como por ejemplo: lo universal por masculino, lo humano por abstracto o lo público por neutral. Muy al contrario, como se ha visto, la idea de igualdad desde un universalismo ético, inclusivo e interactivo descarta tal planteamiento.

\section{IGUALDAD Y GÉNERO}

El entramado normativo y ético que supone una conceptualización universalista de la igualdad guarda un vínculo constitutivo con las críticas de diversas teorías feministas al pensamiento moderno occidental. Si bien una parte de los feminis$\operatorname{mos}^{55}$, como el culturalista, suele abogar por lanzar la universalidad "a las cloacas de la historia" ${ }^{26}$, otra parte se sitúa en un cuestionamiento crítico pero no rupturista ${ }^{57}$. Y esto tiene unas consecuencias claras desde el punto de vista teórico político. Tanto es así que situarse en una u otra corriente puede determinar la posición frente a la propia igualdad como ideal. No obstante, existe un acuerdo más o menos general en torno a lo que Benhabib ha denominado una "falla epis-

${ }^{53}$ Ibid., p. 160.

${ }^{54}$ No solo teórica sino analíticamente sustituir las partes por el todo o viceversa es pretender aquí comprender la complejidad desde la simplicidad — que no sencillez-, lo que implica un reduccionismo desacertado.

${ }^{55}$ Sin duda no existe un único feminismo sino una diversidad de ellos, de ahí que lo correcto sea nombrarlos en plural y no en singular: feminismos.

${ }^{56}$ Elisabeth BADinTer, Por mal camino, Alianza, Madrid, 2004, p. 156.

${ }^{57}$ Véase BENHABIB, El ser y el otro en la ética contemporánea; FrASER, Escalas de justicia; Nussbaum, Las mujeres y el desarrollo humano; y Amy Guttman, La identidad en democracia, Katz, Madrid, 2008. 
témica profunda": la ceguera ante la cuestión de género de gran parte de la teoría universalista moderna y contemporánea ${ }^{58}$.

En este sentido, la reflexión sobre la igualdad que aquí se expone quedaría enmarcada en la segunda corriente ${ }^{59}$. Los supuestos injustificados del universalismo, dice Benhabib, no tienen por qué comprometerlo como tal. Desde el punto de vista ético, un universalismo como propuesta de defensa y promoción de la igualdad, atendiendo a las generalidades y a las especificidades que conforman la idea de sujeto, no solo es plausible sino decisivo. Según Martha Nussbaum, "se requieren normas universales si hemos de proteger la diversidad, el pluralismo y la libertad, tratando a cada ser humano como agente y como un fin en sí" ${ }^{60}$.

La problemática clave que engloba esos supuestos injustificados tiene que ver, una vez más, con nociones más bien fingidas de la universalidad, la abstracción y la neutralidad. En última instancia, se argumenta, estas han sido asimiladas únicamente como norma masculina ${ }^{61}$. Una crítica que forma parte del discurso de larga trayectoria en la literatura feminista respecto a la construcción e interpretación social y cultural del sexo, según la cual se asignan identidades, roles, tareas y espacios a cada uno de los (dos) sexos. Se destaca que, pese al reconocimiento legal y universal de la igualdad, en la práctica la norma se vacía de universalidad, abstracción y neutralidad, quedando identificada con el hombre. Lo masculino aparece como metáfora del poder, a los hombres les pertenece el espacio público y el trabajo productivo. En definitiva, el hombre es el sujeto político capacitado para los asuntos públicos. En el otro lado, la mujer queda enraizada por su condición femenina a la naturaleza, al espacio familiar. Algo incluso visto como una complementariedad funcional de la estructura social ${ }^{62}$. La terminolo-

\footnotetext{
${ }^{58}$ No solo por indiferencia moral o inclinación política. BENHABIB, El ser y el otro en la ética contemporánea, p. 67, passim. 154-155.

${ }^{59}$ A la que quizás podría llamarse feminismo universalista. BADINTER, Por mal camino, pp.

${ }^{60}$ Nussbaum, Las mujeres y el desarrollo humano, p. 154.

${ }^{61}$ Siguiendo el pensamiento de la feminista culturalista Catherine Mackinnon, la igualdad se interpreta como el patrón masculino alcanzado por las mujeres. Desde su óptica, la igualdad abstracta refuerza necesariamente las desigualdades fruto del statu quo ya que, según entiende la autora, la igualdad normativa traduce lo humano en hombre. Catherine MACKINNON, Toward a Feminist Theory of State, Harvard University Press, Cambridge, London, 1989, pp. 227 y ss.

${ }^{62}$ Talcott Parsons y Robert F. BALES, Family, Socialization and Interaction Process, Routledge \& Kegan Paul, Londres, 1956; Talcott Parsons, El sistema social, Biblioteca de la Revista de Occidente, Madrid, 1976; Talcott PARSONS, "La estructura social de la familia", en Erich Fromm et al., La familia, Península, Barcelona, 1970.
} 
gía conceptual como el patriarcado ${ }^{63}$, el sistema sexo-género ${ }^{64} u$ otros, refieren precisamente a esto: a la superioridad, dominación y hegemonía masculina en aras de la universalidad, y la consecuente discriminación, exclusión e infravaloración de las mujeres sobre un bajo continuo de negatividad: lo no masculino, el sexo débil o el segundo sexo ${ }^{65}$.

Esto parece configurar la igualdad como una trampa ingeniosa a partir de la cual se sigue sosteniendo el sistema de dominación masculina ${ }^{66}$. Por consiguiente, la estrategia de la lucha contra la desigualdad estaría en otro lado; un lugar no contaminado por esa falsa of farsa de universalidad. Y ese lugar parece tener su asiento en la seguridad de la diferencia biológica. Lo distinto, lo excepcional, lo único... es lo que da sentido, marca la diferencia y, además, es irrebatible. La pregunta, pues, no sería qué es o qué propone la igualdad sino quiénes somos. Así, sería la identidad la respuesta decisiva para salir de la maquinaria de la dominación. La evidencia de la identidad ${ }^{67}$ se reafirma en el fundamento de las diferencias sexuales. Esta es una perspectiva de las identidades que se distancia de la noción de pluralidad e igualdad que este artículo sostiene.

Desde la óptica de las concepciones sexistas, las diferencias biológicas también construyen la identidad y, además, parecen transmitir en un continuum las

${ }^{63}$ Kate Millet, Política sexual, Cátedra, Madrid, 2010.

${ }^{64} \mathrm{La}$ formulación del sistema sexo/género por Gayle Rubin es un punto de partida fundamental de diversas teorías feministas. Gayle RuBIN, "El tráfico de mujeres: notas sobre la "economía política' del sexo": Nueva Antropología, vol. VIII, n. ${ }^{\circ} 30$ (1986), pp. 95-145. Así, mientras unas destacan la construcción social que media entre la biología y la cultura (feminismo de la igualdad), otras se enfocan en la "correlación simbólica" en base a las diferencias biológicas (feminismo de la diferencia). He tomado la noción de correlación simbólica de: Fernando FERNÁnDEZ-LLEBREZ y Cristina GaraizABAL, "Cambios y persistencias en la construcción de las identidades de género", en Ma Antonia CARo y Fernando Fernández-Llebrez, Buenos tratos: prevención de la violencia sexista, Talasa, Madrid, 2010, p. 141.

${ }^{65}$ Simone De Beauvorr, El segundo sexo, Cátedra, Madrid, 2005.

${ }^{66}$ Este trabajo entiende que es más idóneo el uso de una expresión como discriminación masculina o de género. No obstante, se mantiene el concepto de dominación masculina como, por ejemplo, lo entiende Pierre Bourdieu para hacer hincapié en la separación que este texto quiere mantener al respecto. Pierre Bourdieu, La dominación masculina, Anagrama, Barcelona, 2000. Para una crítica del concepto de dominación masculina puede acudirse a: Fernando FERNÁnDEZLlEBREZ, “¿'Hombres de verdad’? Estereotipo masculino, relaciones entre los géneros y ciudadanía": Foro Interno, vol. 4 (2004), pp. 15-43; Fernando FernándEZ-LlEBrEZ, "Malestares de género: identidad e inclusión democrática”: Foro Interno, vol. 12 (2012), pp. 29-59.

${ }^{67}$ Sin embargo, tal y como destacan Fernández-Llebrez y Garaizabal, la identidad no puede verse como una entidad estática y evidente. La identidad es en realidad un proceso de construcción y deconstrucción en el que intervienen tanto factores sociales como individuales. Fundamentalmente, la noción de identidad "está relacionada con la experiencia de autocohesión de la persona, 
condiciones del cuerpo a las capacidades psicológicas, afectivas y emocionales ${ }^{68}$. Esto abre el frente a una construcción de caracteres que se vuelven costumbres, que reafirman la división y la necesaria complementariedad. Así pues, se trata de una deriva natural de las condiciones del cuerpo que acaban reafirmando las esencias a partir de la construcción mental de lo que es y debe ser un verdadero y auténtico hombre y una verdadera y auténtica mujer ${ }^{69}$. De esta forma, el reconocimiento de una identidad no monolítica, unívoca, inflexible sino abierta, fluida, porosa y fragmentada supondría el propio reconocimiento de la posibilidad de cambio, interactividad, contingencia y pluralidad. Lo cual no pone únicamente en entredicho la propia noción de identidad ${ }^{70}$, sino el propio fundamento de la construcción de las estructuras políticas, culturales y sociales en torno a las diferencias biológicas.

Además, es en el espacio público donde particularmente se hacen visibles las identidades y donde los estereotipos armonizan la realidad. A este respecto, cabe decir que la construcción de las identidades a menudo está impregnada de las creencias generalizadas respecto a la importancia del cuerpo para determinar las características de mujeres y hombres. Sin embargo, como señalan Garaizabal y Fernández-Llebrez, las personas no son "meros receptores pasivos" de las concepciones y las conductas dominantes y hegemónicas que se dan en el espacio público ${ }^{71}$. Aunque la visualización estereotipada de las identidades de género es una realidad, también lo es la autonomía individual para escoger los rasgos que deben conformarlas. La existencia de imágenes totalizantes, que socializan las diferencias naturales, reduce y simplifica a mujeres y hombres en dos grupos homogéneos, dos géneros dicotómicos y jerarquizados, a los que al mismo tiempo se les confiere inmutabilidad, es decir, ausencia de variaciones individuales ${ }^{72}$.

esto es, la posibilidad de darle a nuestras experiencias un sentido de continuidad e igualdad en el tiempo". FernándeZ-Llebrez y Garaizabal, "Cambios y persistencias en la construcción de las identidades de género", p. 134.

${ }^{68}$ Esto tiene que ver con una de las principales críticas que el feminismo de la igualdad realiza al feminismo de la diferencia en tanto que reproduce la estructura sexista que en realidad quiere criticar.

${ }^{69}$ Sin poder siquiera haber alguna alternativa más a tal dicotomía. Véase: FERNÁNDEZ-LLEBREZ, "Malestares de género".

${ }^{70}$ Según Garaizabal y Fernández-Llebrez, esto no quiere decir que la identidad sea un mero lastre. Por el contrario, construir una identidad es algo necesario para la persona porque otorga cierto orden y estabilidad básicos para su desarrollo personal. Aunque esto no inhibe que se trate de un "logro precario". Judith ButLer, Precarious Life. The Powers of Mourning and Violence, Verso, London, 2006. Citado en Fernández-Llebrez y Garaizabal, "Cambios y persistencias en la construcción de las identidades de género", p. 134.

${ }^{71}$ Ibid., p. 137.

${ }^{72}$ Ibid., p. 138. 
Por tanto, esto conllevaría entender la masculinidad y la feminidad como "productos acabados" $" 73$ y, en consecuencia, silenciar las lógicas y los deseos contradictorios y las tensiones que se dan en la construcción de la identidad ${ }^{74}$.

Esta melodía reduccionista en la propia concepción del género, efectivamente, tiene entre sus máximos exponentes la categorización dicotómica, bipolar o binominal de los espacios, las identidades y los significados de los géneros como estancias monolíticas y excluyentes entre sí. Así pues, como alerta Badinter, en realidad estas categorías binarias son peligrosas, "porque diluyen la complejidad de lo real en favor de esquemas simplistas y forzados" ". Por ello, si se asume tanto la pluralidad como la variabilidad de las condiciones y acciones humanas, no puede incurrirse en una simplificación y unificación de la realidad en dos. Al igual que no existe una masculinidad ni una feminidad posibles, sino una multiplicidad de ellas, tampoco se puede insistir en la idea de un único sistema causal que impide la igualdad, como el concepto "obstáculo" de la dominación masculina ${ }^{76}$. Planteamientos totalizantes de este tipo, siguiendo a Badinter, lo que realmente hacen es constreñir los géneros en campos opuestos $\mathrm{y}$, a menudo, solo dos (hombres y mujeres), de manera que se obstaculiza la comprensión, por un lado, de la influencia recíproca entre ellos y, por otro, de su "común pertenencia a la humanidad"

Por ello, en realidad es engañoso confiar en un mundo en donde las diferencias son definitivamente reafirmadas o donde los espacios están completamente delimitados como complementarios. El tradicional debate sobre las fronteras del ámbito público y del privado, por ejemplo, adquiere un significado decisivo de este planteamiento binario ${ }^{78}$. La heterodesignación de estos espacios atiende a una explicación del corte que se viene planteando. Dos ámbitos de lógicas y características propias con dos órdenes diferenciados y suplementarios para hombres y mujeres. En esta estructura, el orden público designado al hombre responde a los rasgos masculinos: activo, artificial, productivo, racional, independiente. Por su parte, el orden privado designado a la mujer responde a los rasgos

${ }^{73}$ Ibidem.

${ }^{74}$ Para Jeffrey Weeks, a menudo no es posible controlar o escoger aquello que se siente o se desea, lo cual puede generar una tensión interna que desestabilice la identidad. No obstante, la autonomía que garantiza la libertad concede la capacidad de actuación frente a ello, es decir, sí es posible elegir qué hacer con esos sentimientos y con esos deseos. Jeffrey WEEKS, El malestar de la sexualidad, Talasa, Madrid, 1992.

${ }^{75}$ Badinter, Por mal camino, p. 61.

${ }^{76}$ Ibid., p. 62.

${ }^{77}$ Ibidem.

${ }^{78}$ Aunque cierta distinción entre lo público y lo privado sea relevante. 
femeninos: pasivo, natural, reproductivo, emocional, dependiente. Desde las teorías feministas, esta concepción de los espacios supone el motor tradicional de reproducción de las desigualdades entre mujeres y hombres que, pese a los cambios que se están experimentando, aún permanecen ${ }^{79}$. Como apunta Benhabib, lo que los movimientos y teorías feministas demostraron en las últimas décadas es que "los modos tradicionales de establecer esta distinción ha formado parte de un discurso de dominación que legitima la opresión y la explotación de las mujeres en el ámbito privado" ${ }^{80}$. En consecuencia, es evidente que la familia como institución constitutiva y armonizadora de lo privado ha permanecido como uno de los centros, si no el máximo exponente, de mayor discriminación y opresión de las mujeres ${ }^{81}$. Y es que en el ámbito familiar, constata Nussbaum, la mujer no es tratada como "fin en sí misma, sino como un agregado o instrumento de las necesidades de los otros" $\$ 2$.

Por tanto, el planteamiento ético de una igualdad universal atiende, según Benhabib, al sostenimiento de un sistema de relaciones de género basado en la "reciprocidad igualitaria" ${ }^{83}$. Un sistema en el cual el respeto íntegro y el reparto de las cargas sean mutuos entre las partes implicadas. Esto quedaría lejos de planteamientos centrados en las esencias, las esferas o las sustancias diferenciales según el sexo. Dibujar un camino de este último tipo es espinoso y problemático, a sabiendas de que en ocasiones puede impregnar el propio planteamiento de la igualdad. Quedaría entonces la pregunta fundamental: ¿de qué forma puede articularse un enfoque transformativo de la igualdad de género que se sostenga desde un universalismo ético que atienda genuinamente a la complejidad del concepto?

\section{El ENFOQUE DE LA IGUALDAD DE GÉNERO}

La igualdad no puede afrontarse teóricamente a partir de una única definición o expresión unívoca sino que es necesaria la combinación de diversas ideas de forma abierta. Por ello, el enfoque de Nancy Fraser es el que mejor encaja con la

${ }^{79}$ En España esto puede constatarse a partir de estudios como el de Teresa del VAlLE (coord.), Modelos emergentes en los sistemas y las relaciones de género, Narcea, Madrid, 2002.

${ }^{80}$ BENHABIB, El ser y el otro en la ética contemporánea, pp. 126 y ss.

${ }^{81}$ Inés ALBERDi, La nueva familia española, Taurus, Madrid, 1999; Nussbaum, Las mujeres y el desarrollo humano, p. 321.

82 "Como una mera reproductora, cocinera, fregadora, lugar de descarga sexual, cuidadora, más que como una fuente de capacidad para elegir y perseguir metas y como una fuente de dignidad en sí misma”. NussBaum, Las mujeres y el desarrollo humano, p. 322.

${ }^{83}$ BENHABIB, El ser y el otro en la ética contemporánea, p. 129. 
concepción de igualdad de género que aquí se propone. Su noción de la "transformación" delimita dos frentes teórico-analíticos centrados tanto en la igualdad formal como en la efectiva: 1) socioeconómico o de redistribución y 2) cultu$\mathrm{ral} /$ simbólico o de reconocimiento.

Según esta autora, en principio debe aclararse algo sobre los discursos de la igualdad y de la diferencia: es un dilema apoyado en una falsa antítesis. Puede decirse que la igualdad significa tratar a las mujeres igual que a los hombres y la diferencia tratar a las mujeres de forma distinta a los hombres, pero esto no supone la representación de dos polos antitéticos que conforman una dicotomía absoluta $^{84}$. Es cierto, según plantea, que tradicionalmente la estrategia de la igualdad con frecuencia ha presupuesto lo masculino como norma y que esto ha distorsionado la perspectiva de lo estándar, neutral y universal. Pero también, que la estrategia de la diferencia normalmente descansa en nociones esencialistas de la feminidad, lo cual ha ayudado en reforzar los estereotipos de género que acaban recluyendo a las mujeres en la típica división de los géneros jerarquizados y dicotómicos. De esta manera, ambas preocupaciones son legítimas, dice Fraser, pero esto no socaba el ideal de igualdad per se, pues tales preocupaciones conciernen únicamente a "determinadas formas inadecuadas de concebir la igualdad" ${ }^{85}$. Por tanto, si la igualdad de género queda a salvo como constructo teórico ¿qué contenido debe asumir como enfoque genuino?

El género, según la académica estadounidense, es una problemática que está atravesada por dos tipos de injusticias que no son mutuamente exclusivas sino que están estrechamente imbricadas: injusticias distributivas e injusticias de reconocimiento. Es una cuestión de colectividades bivalentes, en las que las desigualdades responden tanto a la estructura de las relaciones socioecónomicas como a los patrones culturales de interpretación, comunicación y representación $^{86}$. Con lo cual, no se trataría simplemente de escoger entre políticas redistributivas y políticas de reconocimiento. Por el contrario, en un enfoque genuino ambas son complementarias ${ }^{87}$.

\footnotetext{
${ }^{84}$ Nancy FraSER, Justice Interruptus. Critical Reflections on the "Postsocialist" Condition, Routledge, New York, London, 1997, p. 44.

85 "The worry pertains only to certain inadequate ways of conceiving equality". Ibid., p. 47.

${ }^{86}$ Ibid., p. 12. Tal y como Benhabib lo ve, "las contribuciones de Fraser tienen el mérito de otorgarle al concepto de reconocimiento un contenido empírico y también analítico". Seyla BENHABIB, Las reivindicaciones de la cultura. Igualdad y diversidad en la era global, Katz, Buenos Aires, 2006, p. 127.

${ }^{87}$ Estas dos reivindicaciones son analíticamente diferenciables, aunque "en la práctica...están profundamente implicadas entre sí”. Ibid., p. 130.
} 
Más concretamente, de acuerdo con Fraser, el género es una categoría sometida al principio básico de la estructura socioeconómica pues genera tanto explotación y marginalización como privación ${ }^{88}$. Así, se producen dos divisiones sexuales importantes en ámbitos tan decisivos como el trabajo. Por un lado, una división entre el trabajo remunerado o productivo, donde se asume la responsabilidad de los hombres; y el trabajo no remunerado o reproductivo, donde la responsabilidad es de las mujeres. Y, por otro lado, una división entre el trabajo profesional y bien pagado y el trabajo doméstico y no o mal remunerado, para hombres y mujeres respectivamente.

Pero a su vez, el género responde a la construcción e interpretación cultural del sexo, en tanto en cuanto se consolidan dos tipos de desigualdades fundamentales ${ }^{89}$ : el "androcentrismo" o construcción autoritaria de normas que privilegia los atributos asociados a la masculinidad; y el "sexismo cultural" o devaluación y menosprecio generalizado de la condición femenina (aunque no solo de las mujeres).

En definitiva, estas dos caras de la injusticia de género, concluye la autora, están entrelazadas de tal forma que se refuerzan mutuamente. Y esto es así pues se ha producido una institucionalización, tanto en el ámbito político como en el económico, de las normas culturales sostenidas en patrones sexistas y androcéntricos. Así, la desventaja económica de las mujeres restringe la expresión de sus voces, lo cual impide su igual participación en el hacer cultural, público y de la vida cotidiana. El resultado es un círculo vicioso de subordinación cultural y económica de las mujeres ${ }^{90}$.

La respuesta ante tales injusticias es el planteamiento de dos estrategias imbricadas pero analíticamente distintas: la redistribución y el reconocimiento. Mientras la primera se define por su componente económico, la segunda lo hace por su componente de estatus cultural y simbólico. La estrategia económica se centra en la redistribución de los ingresos, la reorganización de la división del trabajo y el sometimiento a procesos de decisión democráticos de la inversión económica $^{91}$. Por su parte, la estrategia cultural pone en valor las identidades y

${ }^{88}$ Para Fraser la explotación se entiende como el beneficio injusto que se obtiene del trabajo de otros. La marginalización refiere a la inaccesibilidad o mala accesibilidad a los ingresos. Y la privación, a impedir el disfrute de las condiciones materiales mínimas para la vida. FrASER, Justice Interruptus, pp. 13-20.

${ }^{89}$ Estas responden a patrones de dominación cultural, de ausencia o mal reconocimiento de las culturas por la autoridad y de falta de respeto, desprecio y difamación por parte de una cultura pública estereotipada tanto en el estatus público como en las interacciones cotidianas. Ibid., p. 14.

${ }^{90}$ Ibid., p. 21.

${ }^{91}$ Ibid., p. 15. 
los grupos no respetados o difamados así como la diversidad cultural. En resumen, una transformación de la forma de representar, interpretar y comunicar nuestra identidad ${ }^{92}$.

Este enfoque transformativo de la igualdad de género pone sobre la mesa las incoherencias, insuficiencias y tensiones de la idea de igualdad cuando la problemática de género entra en escena. Al comienzo de esta reflexión, con los planteamientos de Dworkin respecto a la igualdad de recursos, Sen y las capacidades para funcionar o Rawls y los bienes primarios, la propuesta de la igualdad se concentraba en dos aspectos: la inherencia y la distribución. Así, con estos dos elementos se erigía una estrategia centrada fundamentalmente en el desarrollo de la libertad como ideal político, a partir una propuesta redistributiva justa que iguale las condiciones de desventaja. Sin embargo, los enfoques de los recursos y del bienestar - con sus particularidades - pueden concebirse como un paso crucial hacia la igualdad y la libertad pero no un "fin en sí mismo"93. La (re)distribución quizás toma mejor forma como anacrusa en la partitura, es decir, notas que dan entrada al tiempo fuerte de la igualdad; que son básicas y que además continúan siendo un elemento fundamental a lo largo de la obra. Pero el reto de la igualdad de género va más allá de un necesario reparto igualitario de los recursos. Como se ha visto partir del enfoque de Fraser, una redistribución de los recursos para combatir las desigualdades no es suficiente.

En este sentido, la interdependencia de la libertad y la igualdad como dos virtudes de un solo ideal político se vuelve fundamental. La noción de pluralismo acorde al respeto de la autonomía individual no permite confiar en la atribución inicial o en la mera consideración de capacidades innatas distintivas para definir una circunstancia igualitaria. No se trata de negar la existencia de facultades o habilidades disímiles entre las personas sino de promover circunstancias, condiciones y relaciones en igualdad de cara al ejercicio de la libertad. De no ser así, se estaría predeterminando la igualdad por las aptitudes en lugar de por las actitudes. Por lo tanto, la predeterminación previa de espacios, roles y/o cualidades de las personas no solo desactiva la igualdad y la libertad sino también la propia noción de comunidad; la identidad cívica que fundamenta la forma de interrelación y comunicación en una sociedad democrática.

En última instancia, la cuestión de género como problemática bivalente atañe no solo las situaciones socioeconómicas que manifiestan desigualdades según los sexos, sino también las formas de representación, comunicación e

92 Ibidem.

93 Jane Franklin (ed.), Equality, Institute for Public Policy Research, London, 1997, p. 4. 
interpretación cultural y simbólica de la diferencia biológica. De ahí que el reto de la igualdad ataje no solo la defensa de un marco normativo y la transformación de las circunstancias y las condiciones que impiden su logro sino también la transformación de las formas de relacionarse ${ }^{94}$. La igualdad, de hecho, debe ir incluso más allá de la redistribución y el reconocimiento. Tal y como Carlos Lomas lo ve, no solo se trata de fomentar un reequilibrio entre los géneros en las esferas política, económica, social y cultural sino que también apremian otros cambios en la vida personal de las mujeres y de los hombres que afectan:

A lo que somos, al modo en que nos entendemos y nos relacionamos, a las maneras en que nos amamos, al valor que otorgamos a los afectos y a las emociones, a las tareas que desempeñamos dentro y fuera del hogar y a la voluntad de contribuir o no a la construcción de un mundo íntimo y público en el que la diferencia sexual no sea nunca más el argumento con el que se intente justificar tanto la subordinación femenina como la dominación masculina ${ }^{95}$.

\section{IGUALDAD DE GÉNERO Y EL RETO DE LA ENARMONÍA ${ }^{96}$}

Decía Simone de Beauvoir (1908-1986) en una entrevista que la mitología en la cual la condición femenina se consideraba una esencia eterna no podría cam-

${ }^{94}$ En este sentido, difiero de la perspectiva de Badinter según la cual el fin último es la instauración de la igualdad de sexos sin tener por ello que mejorar las relaciones entre mujeres y hombres. Según la autora, "no hay que confundir el objetivo con sus consecuencias, aunque a veces se finja creer que los dos van a la par". BADINTER, Por mal camino, p. 149. Es cierto que una transformación paralela de las estructuras como de las relaciones es difícil que vayan a la par. Sin embargo, esto no quiere decir que ambas no sean necesarias, pues de poco puede servir el éxito redistributivo y de reconocimiento si en la práctica las relaciones no se desarrollan de acuerdo al principio igualitario. Esto nos hace ver la igualdad como proceso, como construcción, una igualdad inacabada.

${ }^{95}$ Carlos Lomas, ¿El otoño del patriarcado? Luces y sombras de la igualdad entre mujeres $y$ hombres, Península, Barcelona, 2008, p. 71.

${ }^{96} \mathrm{La}$ enarmonía, la relación enarmónica o el principio enarmónico son fórmulas que en el lenguaje musical definen la relación entre dos o varios sonidos que, en un sistema ajustado o temperado, suenan igual pese a que difieren ampliamente en su significado. Cuando esta relación de igualdad se produce se entiende que un sonido es enarmónicamente equivalente al otro. Walter PISTON, Harmony, LTD, London, 1959. En la teoría musical de la armonía moderna, esta relación enarmónica se define como notas, intervalos, acordes o tonalidades que difieren en nombre pero que coinciden en altura. En particular, las notas enarmónicas son importantes fundamentalmente para los instrumentos de cuerda y la voz ya que no están sometidos a la corrección del sistema de afinación de temperamento igual. En un piano, sin embargo, esta diferencia de alturas es inexistente 
biarse si no se transformaban las estructuras económicas y políticas ${ }^{97}$. Unas estructuras en las que el hombre es claro dominador y, además, reproductor de tal mitología, reinventando la historia según más le convenga. No es de extrañar, por tanto, que las reivindicaciones feministas por la transformación de un sistema de poder desigualitario y discriminante se hayan centrado no solo en la lucha por la redistribución interdependientemente con la del reconocimiento ${ }^{98}$ sino también con la reestructuración de la forma de concebir las relaciones. Así, es igualmente importante destacar las formas de relacionarse y de construir las identidades en las estructuras de las sociedades democráticas actuales. En este sentido, los aportes de la teoría política genuina respecto a lo decisivo de repensar el concepto de ciudadanía democrática son cruciales.

Sheldon S. Wolin entiende que la democracia puede subvertirse a sí misma si somete sus convicciones igualitarias a una estructura de poder en la cual la ciudadanía esté desactivada ${ }^{99}$. Por ello, un requisito indispensable de la democracia es la defensa de una cultura cívica que respalde "un complejo de creencias, valores y prácticas que nutran la igualdad, la cooperación y la libertad"100. El cultivo de relaciones igualitarias requiere, por ende, de aquellas virtudes cívicas que comprenden igual respeto, consideración y participación en el espacio público y, a su vez, de una traducción recíproca en el ámbito privado. Lo cual es incompatible con una interpretación de la igualdad como mera garantía de reparto de recursos o de oportunidades económicas; con una ciudadanía intermitente y pasiva ante arquitecturas políticas y económicas desigualitarias; y con una definición de los espacios, las capacidades y las identidades como prolongaciones de las diferencias biológicas.

Por ello, el enfoque transformativo de la igualdad promueve, entre otras cosas, afinar el oído de la ciudadanía ante la pluralidad y la diversidad de formas de vida y de relacionarse, en donde el florecimiento de relaciones igualitarias

pues, por ejemplo, sol\# y la $b$ son la misma nota pero acústicamente son distintas. Alison LATHAM, Diccionario enciclopédico de la música, Fondo de Cultura Económica, México, 2008, pp. 523, $532,788$.

${ }^{97}$ Entrevista recogida en el reportaje sobre la autora de Informe Semanal: "Adiós a Simone de Beauvoir" (19-4-1986). Disponible en: http://www.rtve.es/alacarta/videos/informe-semanal/informe-semanal-adios-simone-beauvoir-1986/1066415/ (17-5-2015).

${ }^{98}$ Para Benhabib, el análisis de esta interdependencia es uno de los temas fundamentales que enfrentan la sociología y la filosofía política del Estado del Bienestar. BENHABIB, Las reivindicaciones de la cultura, p. 129.

${ }^{99}$ Sheldon S. Wolin, Democracia S.A. La democracia dirigida y el fantasma del totalitarismo invertido, Katz, Buenos Aires, 2008.

${ }^{100}$ Ibid., p. 363. 
permanece acorde a la libertad individual. En este sentido, cabe resaltar un aspecto decisivo en la construcción de la identidad cívica: la virtud de considerar al otro como igual al mismo tiempo que particular.

La igualdad no debe ni negar las diferencias ni interpretarlas sine qua non como desigualdades. No implica la difuminación de las diferencias, sino que estas conviven manteniendo su autonomía. De ahí que la igualdad deba poder captar en abstracto y en concreto la realidad plural y diversa en la que se relacionan las personas. Esos otros generalizados y otros concretos, a los que se hizo referencia a partir del planteamiento de Benhabib, deben estar presentes en el concepto de igualdad, de forma que las voces sean igualmente consideradas $\mathrm{y}$, al mismo tiempo, cada una custodie su libertad e identidad propia. Por tanto, una propuesta transformativa acerca la idea de igualdad a un reto enarmónico. Con este préstamo musical, en realidad, se comprende con soltura la combinación entre la igualdad y las identidades diferentes que conjuga una visión abierta y plural lejos de simetrías y conflictos.

Se ha sostenido a lo largo de este trabajo que, en un sistema democrático reglado o temperado, la igualdad y la libertad en una sociedad plural son aspectos de la misma virtud política. Esto conlleva el reconocimiento de que una persona es igual pero no idéntica a otra y de que la desigualdad no es producto de la diferencia biológica sino de la construcción e interpretación cultural y simbólica de tal diferencia, lo que puede integrar la propia estructura política, económica y social. Por eso, la garantía del pluralismo que la igualdad defiende no es otra cosa que el reconocimiento de la existencia de disonancias y consonancias, conciertos y desconciertos y/o alteraciones y permanencias. Lo que el acuerdo o acorde de la igualdad propugna es que dos voces pueden ser iguales a sabiendas de que no son idénticas, es decir, son enarmónicas. Al mismo tiempo que un re sostenido puede entonarse igual que un mi bemol - en el caso de un piano es exactamente la misma tecla-, ambas notas no solo mantienen una identidad y una connotación musical genuinas — con distinto nombre - sino que, en realidad, su sonido no es exactamente el mismo — no es unísono-.

Si la democracia es ese sistema temperado que se ajusta a un reglaje equilibrado común (isonomía), que iguala las voces (isegoría) en consideración e importancia pero no en identidad, entonces la igualdad no promueve otra cosa que el sostenimiento de una enarmonía política. El éxito de un enfoque transformativo como el de la redistribución y el reconocimiento dependerá, por un lado, de la articulación enarmónica de su propuesta, en tanto se consiga una redistribución igualmente afinada y entonada —una reafinación de la estructura socioeconómica-; y, por otro, de un reconocimiento de las particularidades sin privilegio ni infravaloración alguna. 
La democracia otorga a las consonancias, las disonancias y los silencios un valor igual de importante, teniendo en cuenta que sus significados son diversos. La temperación democrática permite la igualdad. Todas las personas pueden conformar el mismo acorde, la misma tonalidad o la misma nota en un curso de vida contingente, dinámico, abierto, flexible y modulable. Y no se hace de forma virtual sino efectiva a través de la garantía que la fórmula enarmónica permite: igualar sin identificar y liberar sin discriminar.

\section{REFERENCIAS BIBLIOGRÁFICAS}

Alberdi, Inés, La nueva familia española, Taurus, Madrid, 1999.

ARENDT, Hannah, La condición humana, Taurus, Madrid, 2005.

Badinter, Elisabeth, Por mal camino, Alianza, Madrid, 2004.

BAUMAN, Zygmunt, Identidad, Losada, Madrid, 2005.

BenHABIB, Seyla, El ser y el otro en la ética contemporánea. Feminismo, comunitarismo, posmodernismo, Gedisa, Barcelona, 2006.

-, Las reivindicaciones de la cultura. Igualdad y diversidad en la era global, Katz, Buenos Aires, 2006.

BERLIN, Isaiah, El fuste torcido de la humanidad, Península, Barcelona, 1992.

BERMAn, Marshall, Todo lo sólido se desvanece en el aire. La experiencia de la modernidad, Siglo XXI, México, 2006.

Bourdieu, Pierre, La dominación masculina, Anagrama, Barcelona, 2000.

Butler, Judith, Precarious Life. The Powers of Mourning and Violence, Verso, London, 2006.

CoHEN, Gerald A., "¿Igualdad de qué? Sobre el bienestar, los bienes y las capacidades": Comercio Exterior, vol. 53, n. 5 (2003), pp. 427-433.

DAHL, Robert, La democracia y sus críticos, Paidós, Barcelona, 1992.

De Beauvoir, Simone, El segundo sexo, Cátedra, Madrid, 2005.

De Sousa Santos, Boaventura, "La Sociología de las Ausencias y la Sociología de las Emergencias", Encuentro Renovar la teoría crítica y reinventar la emancipación social. Disponible en: http://bibliotecavirtual.clacso.org.ar /ar/libros/edicion/santos/Capitulo\%20I.pdf (29-10-2014).

Del Valle, Teresa (coord.), Modelos emergentes en los sistemas y las relaciones de género, Narcea, Madrid, 2002.

Dworkin, Ronald, Virtud soberana. La teoría y la práctica de la igualdad, Paidós, Barcelona, 2003.

FERNÁNDEZ-LleBreZ, Fernando, “¿'Hombres de verdad’? Estereotipo masculino, relaciones entre los géneros y ciudadanía": Foro Interno, vol. 4 (2004), pp. $15-43$. 
-, "Malestares de género: identidad e inclusión democrática": Foro Interno, vol. 12 (2012), pp. 29-59.

-, "Crítica del libro: El mundo interno y la política de Javier Roiz": Revista Española de Ciencia Política, n. ${ }^{\circ} 34$ (2014), pp. 235-239.

Fernández-Llebrez, Fernando y Garaizabal, Cristina, "Cambios y persistencias en la construcción de las identidades de género", en M $\mathrm{M}^{\mathrm{a}}$ Antonia CARO y Fernando FernándeZ-Llebrez, Buenos tratos: prevención de la violencia sexista, Talasa, Madrid, 2010.

Franklin, Jane (ed.), Equality, Institute for Public Policy Research, London, 1997.

Fraser, Nancy, Justice Interruptus. Critical Reflections on the "Postsocialist" Condition, Routledge, New York, London, 1997.

—, Escalas de justicia, Herder, Barcelona, 2008.

Fromm, Erich, et al., La familia, Península, Barcelona, 1970.

GutTman, Amy, La identidad en democracia, Katz, Madrid, 2008.

Latham, Alison, Diccionario enciclopédico de la música, Fondo de Cultura Económica, México, 2008.

LOMAS, Carlos, ¿El otoño del patriarcado? Luces y sombras de la igualdad entre mujeres y hombres, Península, Barcelona, 2008.

MaCkInNon, Catherine, Toward a Feminist Theory of State, Harvard University Press, Cambridge, London, 1989.

Manin, Bernard, Los principios del gobierno representativo, Alianza, Madrid, 1998.

Mason, Andrew, "Social justice: the place of equal opportunity", en Richard Bellamy y Andrew Mason (eds.), Political Concepts, Manchester University Press, Manchester \& New York, 2003.

Millet, Kate, Política sexual, Cátedra, Madrid, 2010.

Molina Petit, Cristina, Dialéctica feminista de la Ilustración, Dirección General de la Mujer, Barcelona, 1994.

Mouffe, Chantal y Galmarini, Marco A., El retorno de lo político: comunidad, ciudadanía, pluralismo, democracia radical, Paidós, Barcelona, 1999.

Nagel, Thomas, "Equality", en Matthew Clayton y Andrew Williams (eds.), The Ideal of Equality, St. Martin's Press, New York, 2000, pp. 60-80.

PARsons, Talcott, El sistema social, Biblioteca de la Revista de Occidente, Madrid, 1976.

Parsons, Talcott, y Bales, Robert F., Family, Socialization and Interaction Process, Routledge \& Kegan Paul, Londres, 1956.

Piston, Walter, Harmony, LTD, London, 1959. 
Rawls, John, Teoría de la justicia, Fondo de Cultura Económica, México, 2006. RICHARDT, Nicole y SHANKS, Torrey "Equal Opportunity", en William A. DARITY Jr. (ed.), International Encyclopedia of the Social Sciences, Second Edition, vol. 2, Thomson Gale, Michigan, 2008.

RoIz, Javier, La recuperación del buen juicio. Teoría política en el siglo XX, Foro Interno, Madrid, 2003.

—, El mundo interno y la política, Plaza y Valdés, Madrid, 2013.

Rousseau, Jean-Jacques, Discurso sobre el origen y los fundamentos de la desigualdad entre los hombres, Península, Barcelona, 1970.

RTVE, "Adiós a Simone de Beauvoir", emitido en: Informe Semanal (19-41986). Disponible en: http://www.rtve.es/alacarta/videos/informe-semanal/informe-semanal-adios-simone-beauvoir-1986/1066415/ (17-5-2015).

Rubin, Gayle, "El tráfico de mujeres: notas sobre la 'economía política' del sexo": Nueva Antropología, vol. VIII, n. 30 (1986), pp. 95-145.

Salazar, Octavio, Cartografias de la igualdad. Ciudadanía e identidades en las democracias contemporáneas, Tirant lo Blanch, Valencia, 2010.

SARTORI, Giovanni, Aspectos de la democracia, Limusa-Wiley, México, 1965

—, Elementos de teoría política, Alianza, Madrid, 1999.

SEN, Amartya K., Nuevo examen de la desigualdad, Alianza, Madrid, 1995.

Oppenheim, Felix E., "Igualdad", en David L. Sills (dir.), Enciclopedia Internacional de las Ciencias Sociales, vol. 5, Aguilar, Madrid, 1975.

WeEKs, Jeffrey, El malestar de la sexualidad, Talasa, Madrid, 1992.

Wolin, Sheldon S., Democracia S.A. La democracia dirigida y el fantasma del totalitarismo invertido, Katz, Buenos Aires, 2008. 